\title{
Congenital Dyserythropoietic Anemia Type II: molecular analysis and expression of the SEC23B Gene
}

\author{
Francesca Punzo ${ }^{1,2}$, Aida M Bertoli-Avella', Saverio Scianguetta², Fulvio Della Ragione ${ }^{3}$, Maddalena Casale²,
} Luisa Ronzoni ${ }^{4}$, Maria D Cappellini ${ }^{4}$, Gianluca Forni ${ }^{5}$, Ben A Oostra ${ }^{1}$ and Silverio Perrotta ${ }^{2 *}$

\begin{abstract}
Background: Congenital dyserythropoietic anemia type II (CDAll), the most common form of CDA, is an autosomal recessive condition. CDAll diagnosis is based on invasive, expensive, and time consuming tests that are available only in specialized laboratories. The recent identification of SEC23B mutations as the cause of CDAll opens new possibilities for the molecular diagnosis of the disease. The aim of this study was to characterize molecular genomic SEC23B defects in 16 unrelated patients affected by CDAll and correlate the identified genetic alterations with SEC23B transcript and protein levels in erythroid precursors.
\end{abstract}

Methods: SEC23B was sequenced in 16 patients, their relatives and 100 control participants. SEC23B transcript level were studied by quantitative PCR (qPCR) in peripheral erythroid precursors and lymphocytes from the patients and healthy control participants. Sec23B protein content was analyzed by immunoblotting in samples of erythroblast cells from CDAll patients and healthy controls.

Results: All of the investigated cases carried SEC23B mutations on both alleles, with the exception of two patients in which a single heterozygous mutation was found. We identified 15 different SEC23B mutations, of which four represent novel mutations: p.GIn214Stop, p.Thr485Ala, p.Val637Gly, and p.Ser727Phe. The CDAll patients exhibited a 40-60\% decrease of SEC23B mRNA levels in erythroid precursors when compared with the corresponding cell type from healthy participants. The largest decrease was observed in compound heterozygote patients with missense/ nonsense mutations. In three patients, Sec23B protein levels were evaluated in erythroid precursors and found to be strictly correlated with the reduction observed at the transcript level. We also demonstrate that Sec23B mRNA expression levels in lymphocytes and erythroblasts are similar.

Conclusions: In this study, we identified four novel SEC23B mutations associated with CDAll disease. We also demonstrate that the genetic alteration results in a significant decrease of SEC23B transcript in erythroid precursors. Similar down-regulation was observed in peripheral lymphocytes, suggesting that the use of these cells might be sufficient in the identification of Sec23B gene alterations. Finally, we demonstrate that decreased Sec23B protein levels in erythroid precursors correlate with down-regulation of the SEC23B mRNA transcript.

Keywords: Congenital dyserythropoietic anemia, CDA II, SEC23B, Red blood cell, Coat complex protein II

\section{Background}

Congenital dyserythropoietic anemias (CDAs) are a group of rare hereditary disorders characterized by ineffective erythropoiesis and distinct morphological abnormalities of the erythroblasts in the bone marrow

\footnotetext{
* Correspondence: silverio.perrotta@unina2.it

${ }^{2}$ Department of Paediatrics, Second University of Naples, Naples, Italy

Full list of author information is available at the end of the article
}

[1]. CDA type II (CDAII, OMIM 224100), which is transmitted as an autosomal recessive condition, is the most frequent; the main European Registries (German, Italian and French) have counted 367 patients [2]. The clinical picture is characterized by mild to moderate anemia associated with jaundice, splenomegaly, and iron overload [3,4]. In clinical practice, evidence of CDAII is primarily based on bone marrow examination $[5,6]$. 
Confirmation of diagnosis is based on at least one of the following biochemical tests, including: a positive acid serum lysis test with ABO-compatible sera; band 3 protein glycosylation defects evidenced by sodium dodecyl sulphate-polyacrylamide gel electrophoresis (SDSPAGE); a discontinuous double membrane in mature erythroblasts (visible by electron microscopy), and the presence of endoplasmic reticulum (ER)-specific proteins [5,7-9]. However, these tests are expensive, time consuming, and often available in only a few specialized laboratories. For these reasons, the correct diagnosis of CDAII is often delayed or erroneously suspected.

A major breakthrough in CDAII research was achieved in 2009, when Schwarz et al. and Bianchi et al. found mutations of the $S E C 23 B$ gene in patients with CDAII $[10,11]$. Sec23B protein is an essential component of coat protein complex II (COPII), coated vesicles that transport secretory proteins from the ER to the Golgi complex [12]. So far, SEC23B changes have been identified mainly by direct genomic sequencing of the coding region of the gene [10,11,13-15]; however, the precise effects of the described mutations on the RNA expression level in erythroid cells has not been studied. Moreover, a reduction of Sec23B protein in CDAII erythroid precursors has not been reported.

In this study, we investigated SEC $23 B$ gene mutations, by both genomic and cDNA direct sequencing, in 16 unrelated Italian CDAII patients from 16 families. In all cases, we identified SEC $23 B$ mutations, and four of these were novel. We also evaluated the effects of different SEC23B mutations on mRNA and protein expression levels.

\section{Methods}

\section{Patients}

We collected blood samples from 16 unrelated Italian CDAII patients belonging to 16 families and 100 unrelated Italian controls (included in the DNA sequence analyses). The diagnosis of CDAII was made on the basis of clinical features, bone marrow examination, and/or SDS-PAGE. All patients provided their written informed consent for the study, which was approved by the research ethics committee of the Second University of Naples, Italy. The study was conducted in accordance with the Declaration of Helsinki.

\section{Erythroid precursor cultures}

After informed consent had been obtained, peripheral blood from CDA II patients and from 5 healthy control relatives was collected into sterile heparinised tubes. Light-density mononuclear cells obtained by centrifugation on Lymphoprep (Nycomed Pharma) density gradient were enriched for $\mathrm{CD}_{3}{ }^{+}$cells by positive selection using CD34 microbeads (Miltenyi Biotech) according to the manufacturers' instructions. CD $34^{+}$cells were cultured at a density of $10^{5}$ cells $/ \mathrm{mL}$ in alpha-minimal essential medium ( $\alpha$-MEM; GIBCO) supplemented with $30 \%$ fetal bovine serum (FBS; GIBCO), as previously described [16]. To induce cells proliferation and erythroid differentiation, cells were cultured with $20 \mathrm{ng} / \mathrm{mL}$ $\mathrm{rH}$ stem cell factor (SCF, PeproTech), $10 \mathrm{ng} / \mathrm{mL} \mathrm{rH}$ interleukin-3 (IL-3, PeproTech) and $3 \mathrm{U} / \mathrm{mL}$ recombinant human $(\mathrm{rH})$ erythropoietin (rHuepo, JanssenCilag). Cells were incubated at $37^{\circ} \mathrm{C}$ with an atmosphere of $5 \% \mathrm{CO}_{2}$ for 14 days; after 7 days of culture the medium was changed to ensure good cells feeding. Cell samples were collected on days 14 of culture (mature erythroblast stage) for further analysis.

\section{Molecular analysis of the SEC23B gene}

Genomic DNA was isolated using the Flexigene DNA extraction kit (Qiagen). All SEC23B exons, their flanking splice junctions, and their 5'- and 3'-untranslated regions were amplified with 21 polymerase chain reactions (PCRs). cDNA was prepared, using the iScript cDNA synthesis kit (Bio-Rad), from approximately 100 ng mRNA obtained from lymphocytes (Trizol Reagent Kit - Invitrogen) from all 16 patients and 8 healthy control relatives. cDNA was obtained also from erythroblasts [16] from 8 patients (ID: F1, G2, B3, A4, C5, $\mathrm{B} 11 \mathrm{P} 13$, and M15) and 5 of the 8 healthy control relatives mentioned above. The coding region of the SEC 23B cDNA was covered by six PCR fragments. Sequences of all primers can be found in Table 1 . The PCR conditions were: $94^{\circ} \mathrm{C}$ for $5 \mathrm{~min}$; 30 cycles of $94^{\circ} \mathrm{C}$ for $30 \mathrm{sec}, 58^{\circ} \mathrm{C}$ for $30 \mathrm{sec}$ and $72^{\circ} \mathrm{C}$ for $30 \mathrm{sec}$; and $72^{\circ}$ $\mathrm{C}$ for $7 \mathrm{~min}$. Amplified DNA and cDNA were purified (Exo-Sap-IT) and sequenced using BDT v3.1 on an ABIPrism 3130XL genetic analyzer. Sequences were analyzed using the SeqScape program, version 2.6 (Applied Biosystems).

Table 1 Primer sequences for SEC23B cDNA amplification

\begin{tabular}{ll}
\hline Oligo Name & Oligo Sequence \\
\hline SEC23B CDNA 1F & ACCTGTCTTGCCCTGTTCC \\
SEC23B CDNA 1R & TACAGGCCCAAAGTTTGCT \\
SEC23B CDNA 2F & AGCAGGCCAACTTGTAAAGC \\
SEC23B CDNA 2R & CTTGAAGCAAAAGGTGCTC \\
SEC23B CDNA 3F & ACAGGATATGTTGGCCTGA \\
SEC23B CDNA 3R & TTGCACAACACTTCATCTCCA \\
SEC23B CDNA 4F & GAACAGCTGCAAATGGTCAC \\
SEC23B CDNA 4R & CACAGTCGGATGAGTTTCG \\
SEC23B CDNA 5F & GACCGACAACTCATCCGACT \\
SEC23B CDNA 5R & TTCCTGTCCCCAAGCATAC \\
SEC23B CDNA 6F & CAGTCAGGCTCGATTCCTTT \\
SEC23B CDNA 6R & CACCTAAACAAGCTGCCAAA \\
\hline
\end{tabular}




\section{Real-time PCR}

cDNA was prepared from patients' mRNA from lymphocytes and erythroblasts. Real-time PCR was performed in accordance with manufacturers' instructions. The reactions were run on an ABI 7300 real-time PCR system (Applied Biosystems); the cycling conditions were $10 \mathrm{~min}$ at $95^{\circ} \mathrm{C}$ (initial denaturation) followed by 40 cycles of $15 \mathrm{sec}$ at $94^{\circ} \mathrm{C}$ (denaturation) and $1 \mathrm{~min}$ at $68^{\circ} \mathrm{C}$ (annealing/extension/data collection). In the first step, we determined the stability of a control gene $(\beta$ actin) for the normalization of the real-time PCR products. The linearity and efficiency of this assay were tested over dilutions of input cDNA spanning five orders of magnitude. Assays were performed in triplicate. We used the $2^{-\Delta \Delta \mathrm{Ct}}$ method to analyze the data obtained.

\section{Western blotting}

Proteins were extracted from erythroid cultures of patients A4, B3, and C5 using RIPA Lysis Buffer (Millipore) and following the manufacturer's instructions. Sec23B was characterized in total lysates from erythroid cultures by Western blotting. Membranes were incubated overnight at $4{ }^{\circ} \mathrm{C}$ with rabbit polyclonal antiSec23B antibody (1:500 dilution; SAB2102104, SigmaAldrich); reactive bands were detected by chemiluminescence (SuperSignal). An anti- $\beta$-actin antibody (1:500 dilution; Sigma) was used to check for comparable protein loading and as a housekeeping protein. Images were captured, stored, and analyzed using Quantity One software (BioRad).

\section{Results}

Molecular analysis of the SEC23B gene

We identified $S E C 23 B$ mutations in all 16 patients enrolled in the study. Among the 15 mutations characterized, four are novel: c.640C > T, c.1453A > G, c. $1910 \mathrm{~T}>\mathrm{G}$, and c. $2180 \mathrm{C}>\mathrm{T}$ (Table 2). In total, we identified 10 missense, three nonsense, one in-frame deletion of 3 nucleotides, and one splice-site mutation. The splice-site alteration creates a new donor site after exon 2 of the $S E C 23 B$ gene. Most of the investigated patients were compound heterozygotes. Only four patients had homozygous SEC $23 B$ mutations; three of these were homozygotes for the c.325G > A variant that leads to the amino acid change p.Glu109Lys (the most frequent $S E C 23 B$ mutation encountered, with a prevalence of $32 \%$ among CDAII patients). The fourth patient was homozygous for the c.1254T > G mutation (p. Ile418Met).

In two patients, we observed only a single heterozygous mutation (Table 2). Because individuals with a heterozygous $S E C 23 B$ mutation are not affected by CDAII, we investigated in detail the putative occurrence of heterozygous exon deletions/insertions in the alternative allele in these patients. PCR of cDNA using primers located in the 5' and 3' untranslated regions of the gene revealed full-length transcript in both patients and no aberrant products, excluding the presence of heterozygous exon deletions/insertions. cDNA sequence analysis confirmed the heterozygous missense mutation and the presence of two alleles (i.e., wild-type and mutant).

Table 2 SEC23B mutations in 16 Italian patients

\begin{tabular}{|c|c|c|c|c|c|}
\hline $\begin{array}{c}\text { Patient } \\
\text { ID }\end{array}$ & $\begin{array}{c}\text { Allele } \\
1 \\
\end{array}$ & $\begin{array}{c}\text { Allele } \\
2 \\
\end{array}$ & $\begin{array}{c}\text { Protein } \\
\text { change } 1\end{array}$ & $\begin{array}{c}\text { Protein } \\
\text { change } 2\end{array}$ & $\begin{array}{c}\text { CDNA } \\
\%\end{array}$ \\
\hline F1 & c.953 T > C & c.1910 T > G & p.lle318Thr & p.Val637Gly & 55 \\
\hline $\mathrm{G} 2$ & c. $40 \mathrm{C}>\mathrm{T}$ & C.1015 C > T & p.Arg14Trp & p.Arg339X & 42 \\
\hline B3 & c.325 G > A & $c .325 \mathrm{G}>\mathrm{A}$ & p.Glu109Lys & p.Glu109Lys & 60 \\
\hline A4 & IVS1 $+31 \mathrm{~A}>\mathrm{G}$ & c.367 C > T & Donor site ins & p.Arg123X & 36 \\
\hline C5 & c. $40 \mathrm{C}>\mathrm{T}$ & c.1857-1859delCAT & p.Arg14Trp & p.1619del & 54 \\
\hline $\mathrm{C} 6$ & c. $40 \mathrm{C}>\mathrm{T}$ & C.2101 C > T & p.Arg14Trp & p.Arg701Cys & 62 \\
\hline P7 & c. $40 \mathrm{C}>\mathrm{T}$ & c.1015 C > T & p.Arg14Trp & p.Arg339X & 42 \\
\hline C9 & c. $40 \mathrm{C}>\mathrm{T}$ & - & p.Arg14Trp & - & 58 \\
\hline D10 & c. $325 \mathrm{G}>\mathrm{A}$ & c. $325 \mathrm{G}>\mathrm{A}$ & p.Glu109Lys & p.Glu109Lys & 60 \\
\hline B11 & c. $1453 \mathrm{~A}>\mathrm{G}$ & C.1589 G > A & p.Thr485Ala & p.Arg530Gln & 55 \\
\hline P13 & c. $40 \mathrm{C}>\mathrm{T}$ & c. $640 \mathrm{C}>\mathrm{T}$ & p.Arg14Trp & p.Gln214X & 50 \\
\hline G14 & c. $325 \mathrm{G}>\mathrm{A}$ & c. $325 \mathrm{G}>\mathrm{A}$ & p.Glu109Lys & p.Glu109Lys & 61 \\
\hline M15 & c. $40 \mathrm{C}>\mathrm{T}$ & c. $2180 \mathrm{C}>\mathrm{T}$ & p.Arg14Trp & p.Ser727Phe & 55 \\
\hline F16 & c. $325 \mathrm{G}>\mathrm{A}$ & $C 716 A>G$ & p.Glu109Lys & p.Asp239Gly & 61 \\
\hline P17 & $c .40 \mathrm{C}>\mathrm{T}$ & - & p.Arg14Trp & - & 64 \\
\hline E18 & c.1254 T> G & c.1254 T> G & p.lle418Met & p.lle418Met & 53 \\
\hline
\end{tabular}

Novel mutations are bold 
We also sequenced $S E C 23 B$ cDNA from the 16 CDAII patients. In all cases, the mutations identified by genomic analysis were confirmed by cDNA sequencing. Even in the patients carrying nonsense mutations (which most likely lead to RNA decay), it was possible to visualize the genetic change by cDNA sequencing (Figure 1A). None of the novel mutations described in this study was found in 100 unrelated Italian controls. All mutations were absent from the 1094 individuals from the $1000 \mathrm{Genomes}$ project.

\section{Real-time PCR}

To directly evaluate the consequences of the genomic $S E C 23 B$ mutations, we investigated SEC23B mRNA levels in patients and healthy individuals using quantitative PCR (qPCR). Patients that were compound heterozygotes for a missense and a nonsense mutation exhibited a drastic decrease in mRNA expression levels of approximately $50-60 \%$ when normalized to the endogenous control gene $\beta$-actin (Table 2 and Figure $1 B)$. Patients with two missense mutations showed a milder reduction in $S E C 23 B$ mRNA levels (approximately 40-45\%) (Table 2). The results were similar when using RNA from lymphocytes or mature erythroblasts (Figure 1B and data not shown). The two patients with a single heterozygous mutation on SEC23B (C9 and P17) also exhibited a reduction of SEC23B transcript (Table 2).

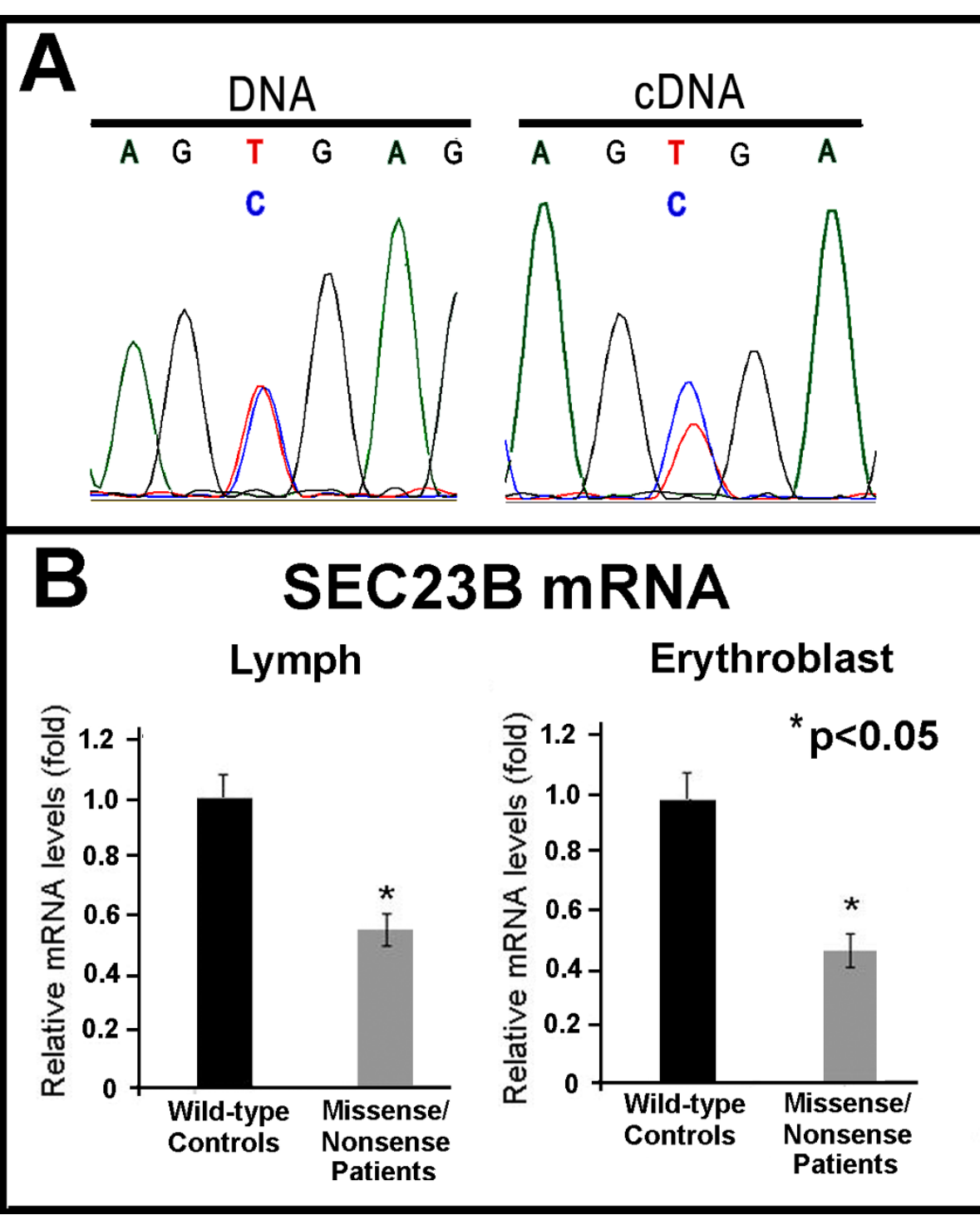

Figure 1 A) Electropherogram depicting the nonsense mutation (c.367C > T) observed after DNA and cDNA sequencing; B) Relative $S E C 23 B$ mRNA expression levels in lymphocytes and erythroblasts from patients with nonsense/missense mutations compared with healthy controls. 
Patient A4 was compound heterozygote for a splicing mutation (c.221+31A > G) and a nonsense change (c.367C > T). In this individual, we suspected very low or no wild-type (WT) transcript. Therefore, we investigated A4 SEC23B mRNA more in detail. First, the presence of the $+31 \mathrm{~A}>\mathrm{G}$ allele was confirmed on agarose gel by the presence of an additional 31-bp band. In the other allele, the nonsense mutation creates a restriction site for the enzyme HpyCH4III. After enzymatic digestion of the PCR product with $\mathrm{HpyCH} 4 \mathrm{III}$ restriction enzyme, we observed four fragments: an upper band for the $+31 \mathrm{~A}<\mathrm{G}$ allele, two lower bands representing the cut allele carrying the nonsense mutation, and a normal-sized band (Figure 2). The occurrence of a normal transcript indicates that at least a small amount of WT $S E C 23 B$ RNA is present. This finding corresponds to the observed 35-40\% SEC23B mRNA expression level measured by qPCR.

\section{Western blotting}

Finally, we investigated the amount of Sec23B protein in the erythroblasts of 3 CDAII patients (C5, B3 and A4) by immunoblotting. The Sec23B content was normalized to $\beta$-actin. As depicted in Figure 3A, the Sec23B content of patients $\mathrm{C} 5$ and B3 was clearly reduced compared to two different controls. Similar results were obtained in two independent experiments. Moreover, the estimated Sec23B protein level in erythroblasts from patient A4 suggested that it corresponded to approximately $30-35 \%$ of that of a healthy individual (Figure 3B). Therefore, our data suggest good correspondence between the transcript amount and protein content, underscoring the usefulness of mRNA evaluation.

\section{Discussion}

In this study, we identified four novel $S E C 23 B$ gene mutations by analyzing 16 Italian patients with CDAII (Table 2). We also identified two CDAII patients with only one heterozygous mutation each.

Since the initial identification of $S E C 23 B$ mutations in CDAII patients, 59 mutations have been identified, including the current work (Table 3) $[10,11,13-15,17,18]$. Two missense mutations have been repeatedly identified in a large proportion of patients: p.Glu109Lys and p.

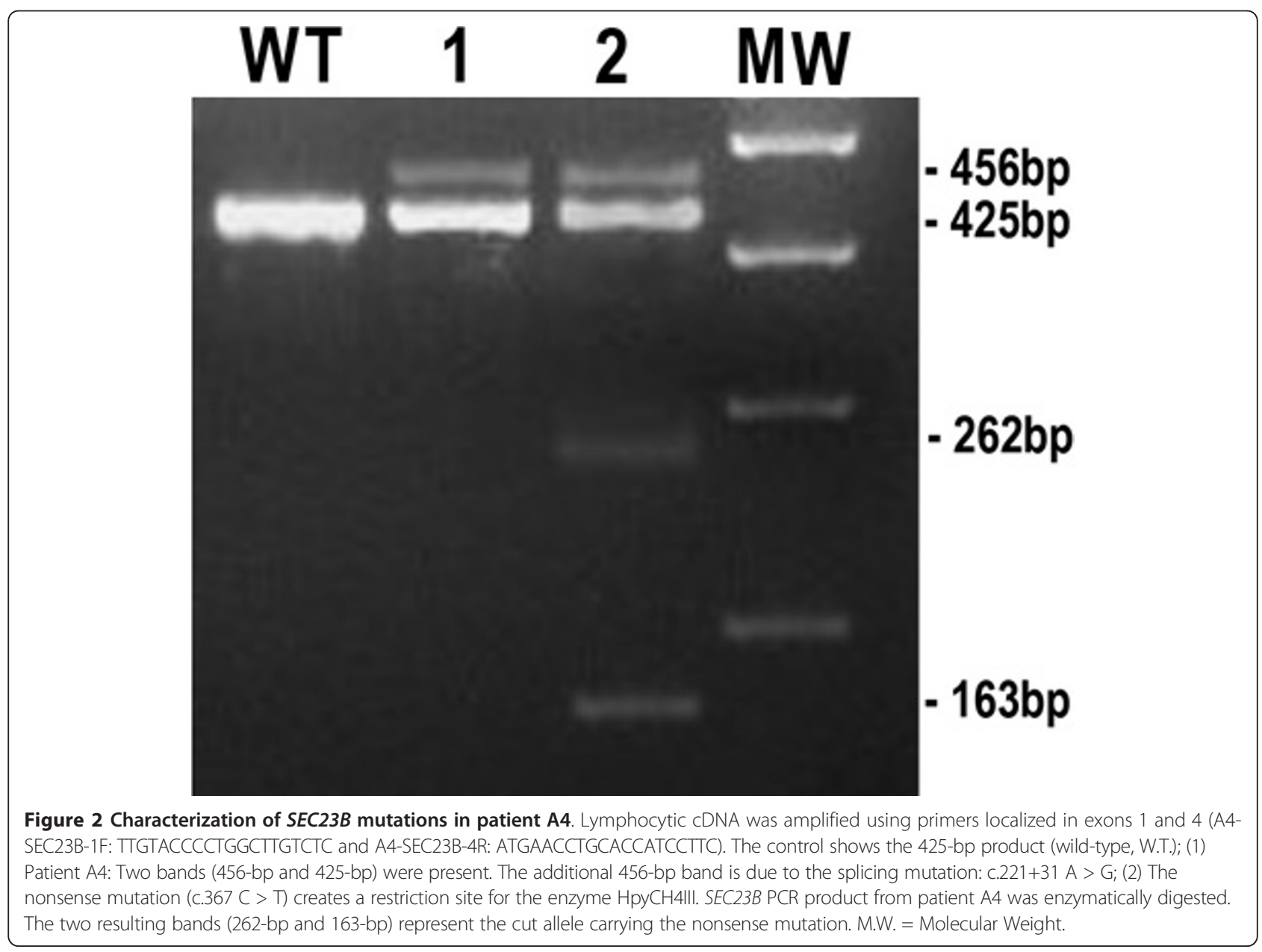




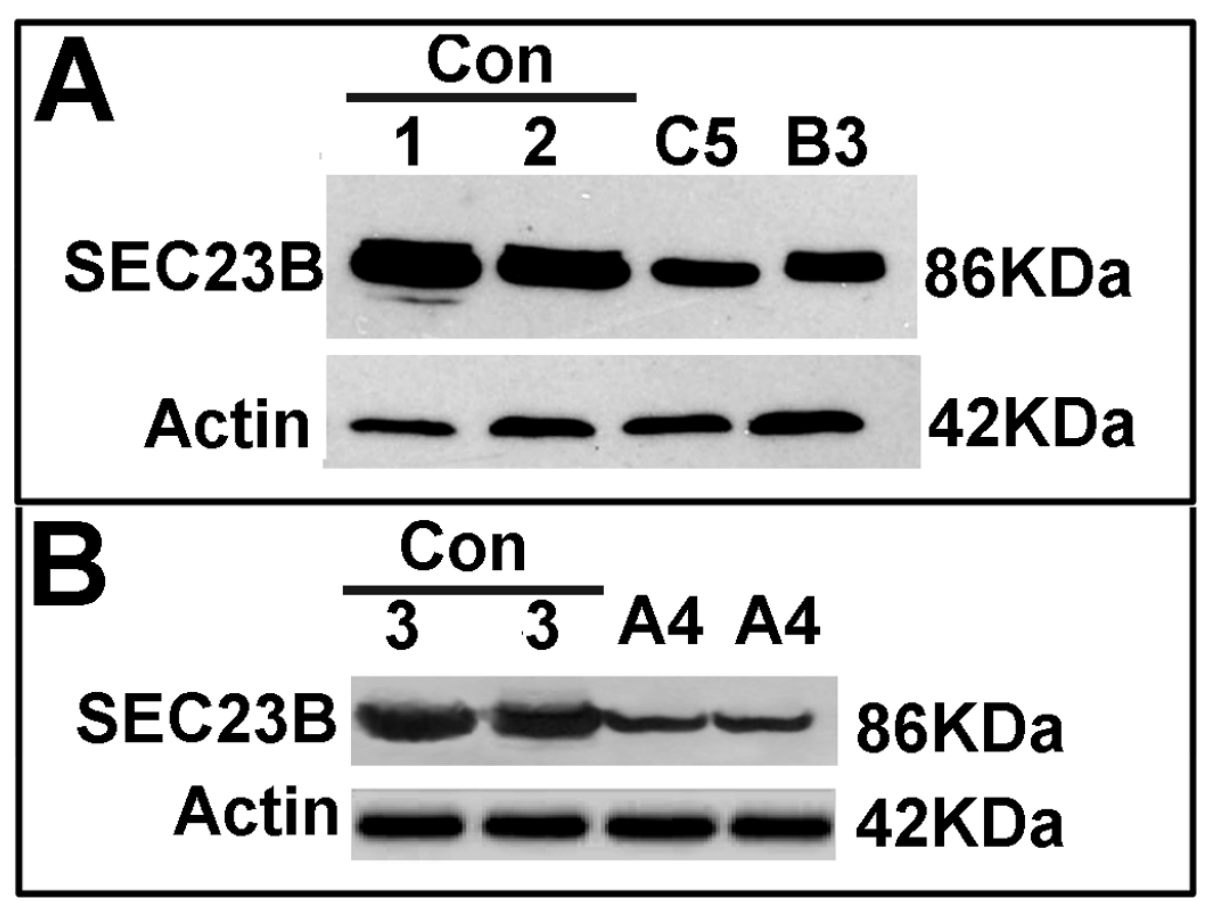

Figure 3 Sec23B protein analysis in erythroid precursors. Western blots from patients C5 and B3 (panel A), and A4 (panel B) demonstrate reduced Sec23B expression compared with control participants (Con). Approximately $40 \mu \mathrm{g}$ of protein were loaded. $\beta$-actin was used as a loading control. The experiment was representative of two different experiments.

Arg14Trp (32\% and 19\%, respectively). To date, these missense mutations account for approximately $50 \%$ of the mutant alleles in CDAII patients (Table 3). Notably, evidence of a founder effect has been described for $\mathrm{p}$. Glu109Lys among Israeli Moroccan Jewish patients [13]. Concerning mutation type, missense (52\%) and nonsense (21\%) mutations are the most commonly observed followed by deletions or insertions that lead to frameshifts in the nucleotide sequence. Splicing mutations are rare, with only six mutations reported (Table 3 ).

The $S E C 23 B$ gene appears to play a pivotal and probably unique function in erythroid precursors $[19,20]$. Although detailed genetic analyses have been conducted, the effects of the mutations on mRNA content in erythroblast cells have not been documented. Moreover, no data are available about the effects of mutations on Sec23B protein content in red cell precursors.

To evaluate the effect of missense and nonsense mutations on $S E C 23 B$ mRNA expression levels, we performed quantitative (qPCR) analysis of $S E C 23 B$ transcripts on all of our patients. In this study, we used both cDNAs prepared from erythroid precursor cultures and peripheral lymphocytes. Although we demonstrate that all patients have a significant reduction of $S E C 23 B$ mRNA, this reduction was more pronounced in patients with missense/nonsense mutations (Table 2). From a diagnostic point of view, it is interesting to note that the results obtained in erythroid precursors and lymphocytes were comparable, suggesting that peripheral lymphocytes not only represent a good source of $S E C 23 B$ transcript, but also replicate the effect of the genetic change observable in the erythroid population.

In addition, to search for genotype-phenotype correlation, we grouped patients according to their degree of anemia. We did not observe any correlation between degree of anemia, type of mutation, and relative $S E C 23 B$ mRNA reduction (data not shown).

Almost all CDAII patients harbor mutations in both $S E C 23 B$ alleles. In a few cases (10 out of 111 described in the literature, or $9 \%$ ), only a single heterozygous $S E C 23 B$ mutation has been found. This finding raises the possibility of the occurrence of mutations that have thus far escaped the exon screening technology. In our study, two CDAII patients were identified in whom a mutation was observed in only one allele. In these participants, mRNA analysis (cDNA sequencing and longrange PCR on CDNA) confirmed the presence of both wild-type and mutated alleles. However, qPCR analysis revealed a reduction in $S E C 23 B$ mRNA expression of approximately $40 \%$ in these patients compared with control participants, similar to the reduction observed in patients with two missense mutations. This finding suggests the possible occurrence of mutations that affect the regulatory regions of the $S E C 23 B$ gene. Alternate 
Table 3 Summary of all SEC23B mutations in CDAll patients, predicted effect on protein and allelic frequencies

\begin{tabular}{|c|c|c|c|c|c|}
\hline Exon/Intron & Nucleotide change & Protein change & Type of mutation & Allelic frequency, n (\%) & References \\
\hline 2 & c. $40 \mathrm{C}>\mathrm{T}$ & p.Arg14Trp & Missense & $48(19)$ & [11] \\
\hline $2-3$ & $c .221+31 \quad A>G$ & - & Splice-site change* & $2(0.8)$ & [14] \\
\hline 2 & C.53 G > A & p.Arg18His & Missense & $3(1.2)$ & [11] \\
\hline 2 & c.197 G > A & p.Cys66Tyr & Missense & $1(0.4)$ & [17] \\
\hline 3 & c. $235 C>T$ & p.Arg79x & Non-sense & $3(1.2)$ & [11] \\
\hline $3-4$ & c. $279+3 \mathrm{~A}>\mathrm{G}$ & - & Splice-site change & $1(0.4)$ & [14] \\
\hline $3-4$ & c.222-817_366+4242del & - & Frame-shift & $1(0.4)$ & [11] \\
\hline 4 & c. $325 \mathrm{G}>\mathrm{A}$ & p.Glu109Lys & Missense & $81(32)$ & [11] \\
\hline 5 & c.367 C > T & p.Arg123X & Non-sense & $2(0.8)$ & [14] \\
\hline 5 & c.387(delG) & p.Leu129LeufsX26 & Frame-shift & $1(0.4)$ & [14] \\
\hline 5 & c.428delAinsCG & - & Frame-shift & $1(0.4)$ & [10] \\
\hline 5 & c.568 C > T & p.Arg190X & Non-sense & $1(0.4)$ & {$[10]$} \\
\hline 6 & c. $640 \mathrm{C}>\mathrm{T}$ & p.G $\ln 214 X$ & Non-sense & $1(0.4)$ & Present study \\
\hline 6 & c.649 C > T & p.Arg217X & Non-sense & $4(1.6)$ & {$[10]$} \\
\hline $6-7$ & c. $689+1 G>A$ & - & Splice-site change & $4(1.6)$ & [10] \\
\hline 7 & c.716 A > G & p.Asp239Gly & Missense & $3(1.2)$ & [11] \\
\hline 7 & c.790 C > T & p.Arg264X & Non-sense & $3(1.2)$ & [11] \\
\hline 8 & c.938 G > A & p.Arg313His & Missense & $4(1.6)$ & [11] \\
\hline 8 & C.953 T > C & p.lle318Thr & Missense & $6(2.4)$ & [11] \\
\hline 8 & c.970 C > T & p.Arg324X & Non-sense & $2(0.8)$ & [11] \\
\hline 9 & c.1015 C > T & p.Arg339X & Non-sense & $3(1.2)$ & [14] \\
\hline 9 & C.1043 A > C & p.Asp348Ala & Missense & $1(0.4)$ & {$[10]$} \\
\hline 9 & c.1063delG & - & Frame-shift & $1(0.4)$ & [11] \\
\hline $9-10$ & c. $1109+5 \mathrm{G}>\mathrm{A}$ & - & Splice-site change & $1(0.4)$ & [14] \\
\hline $9-10$ & c. $1190+1 \mathrm{G}>\mathrm{A}$ & - & Splice-site change & $1(0.4)$ & [14] \\
\hline 10 & C.1157 A > T & p.GIn353Leu & Missense & $1(0.4)$ & [11] \\
\hline 10 & c.1201 C > T & p.Arg401X & Non-sense & $1(0.4)$ & [11] \\
\hline 11 & c. $1254 \mathrm{~T}>\mathrm{G}$ & p.lle418Met & Missense & $3(1.2)$ & [14] \\
\hline 11 & c. $1276 \mathrm{G}>\mathrm{A}$ & p.V426I Poly & Missense & $2(0.8)$ & [11] \\
\hline 11 & c.1307 C > T & p.Ser436Leu & Missense & $1(0.4)$ & [14] \\
\hline 12 & C.1385 A > G & p.Tyr462Cys & Missense & $6(2.4)$ & {$[11]$} \\
\hline 13 & c. 1453 A > G & p.Thr485Ala & Missense & $1(0.4)$ & Present study \\
\hline 13 & c. 1489 C > T & p.Arg497Cys & Missense & 9 (3.6) & {$[10]$} \\
\hline 13 & c. $1508 \mathrm{G}>\mathrm{A}$ & p.Arg503Gln & Missense & $1(0.4)$ & [18] \\
\hline 14 & C.1571 C > T & p.Ala524Val & Missense & $5(2)$ & [11] \\
\hline 14 & c.1588 C > T & p.Arg530Trp & Missense & $1(0.4)$ & [11] \\
\hline 14 & c. $1589 \mathrm{G}>\mathrm{A}$ & p.Arg530Gln & Missense & $2(0.8)$ & [18] \\
\hline 14 & c.1603 C > T & p.Arg535X & Non-sense & $2(0.8)$ & [14] \\
\hline 14 & C.1648 C > T & p.Arg550X & Non-sense & $4(1.6)$ & [18] \\
\hline 14 & c.1654 C > T & p.Leu552Phe & Missense & $1(0.4)$ & [14] \\
\hline 14 & c. $1660 \mathrm{C}>\mathrm{T}$ & p.Arg554X & Non-sense & $2(0.8)$ & [10] \\
\hline 15 & c.1685 A > G & p.Tyr562Cys & Missense & $1(0.4)$ & [18] \\
\hline 15 & c.1733 T > C & p.Leu578Pro & Missense & $2(0.8)$ & [14] \\
\hline 15 & c. $1735 \mathrm{~T}>\mathrm{A}$ & p.Tyr579Asn & Missense & $1(0.4)$ & [14] \\
\hline 16 & c.1808 C > T & p.Ser603Leu & Missense & $1(0.4)$ & [10] \\
\hline 16 & c.1821delT & - & Frame-shift & $3(1.2)$ & [10] \\
\hline 16 & c.1832 G > C & p.Arg611Pro & Missense & $1(0.4)$ & [14] \\
\hline 16 & C.1858 A > G & p.Met620Val & Missense & $2(0.8)$ & [14] \\
\hline 16 & c.1857_1859delCAT & p.lle619del & In frame deletion** & $2(0.8)$ & [14] \\
\hline 17 & c.1910 T > G & p.Val637Gly & Missense & $1(0.4)$ & Present study \\
\hline 17 & c.1962-64delT & p.Thr654ThrfsX13 & Frame-shift & $1(0.4)$ & [18] \\
\hline
\end{tabular}


Table 3 Summary of all SEC23B mutations in CDAll patients, predicted effect on protein and allelic frequencies (Continued)

\begin{tabular}{|c|c|c|c|c|c|}
\hline 17 & c.1968 T > G & p.Phe656Leu & Missense & $1(0.4)$ & [18] \\
\hline 18 & c. $2101 \mathrm{C}>\mathrm{T}$ & p.Arg701Cys & Missense & $9(3.6)$ & [10] \\
\hline 18 & c.2129 C > T & p.Thr710Met & Missense & $1(0.4)$ & [13] \\
\hline $18-19$ & c. $2149-2 A>G$ & - & Splice-site change & $2(0.8)$ & [14] \\
\hline 19 & c.2150(delC) & p.Ala717ValfsX7 & Frame-shift & $1(0.4)$ & [14] \\
\hline 19 & c. $2166 \mathrm{~A}>\mathrm{C}$ & p.Lys723Gln & Missense & $1(0.4)$ & [18] \\
\hline 19 & c. $2180 \mathrm{C}>\mathrm{T}$ & p.Ser727Phe & Missense & $1(0.4)$ & Present study \\
\hline 20 & c. $2270 \mathrm{~A}>\mathrm{C}$ & p.His757Pro & Missense & $1(0.4)$ & [14] \\
\hline
\end{tabular}

${ }^{*}$ creation of a new donor site

**1 aminoacid deletion

mechanisms such as microRNA dysregulation could be responsible for CDAII in these cases where the second heterozygote mutation has not been found.

Here we demonstrate that $S E C 23 B$ mutations result in reductions of both the relative transcript and protein content in erythoid precursors. So far, only one study has investigated protein levels of Sec23B in CDAII patients [11]. No reduction of Sec23B protein levels was observed, most likely due to the type of cell used in the study (fibroblasts). Our data, although comprising a small number of cases, clearly demonstrate that CDAII erythroblastoid cells show a strong reduction of the protein that parallels the data regarding mRNA levels. Future investigations are necessary to clarify the effect of protein reduction on the patients' phenotype.

Patients lacking Sec23B expression have never been described. We identified a single patient (A4) with a nonsense mutation and a splice site mutation (c.221+31 A $>$ G) that causes a stop codon after exon 1. In our view, this patient could have had a very strong reduction of Sec23B expression. On the basis of this hypothesis, we analyzed the amount of $S E C 23 B$ mRNA and protein in this patient in detail. The results demonstrate that there is still a small amount of WT SEC23B mRNA and that the Sec23B protein level in this patient corresponds to $30 \%$ of the level observed in healthy participants, suggesting that the absence of $S E C 23 B$ expression may be lethal.

\section{Conclusions}

This study reports $S E C 23 B$ gene mutations in all 16 CDAII patients studied, confirming the causative relevance of the gene to the condition. We also demonstrated that the $S E C 23 B$ gene mutations lead to a remarkable reduction of $S E C 23 B$ transcript in erythroid precursors, the cell type altered in the disease. We also demonstrated that quantifying and sequencing $S E C 23 B$ mRNA from peripheral lymphocytes (and not only from erythroid cultures) might facilitate the genetic diagnosis of CDAII. Our data on heterozygote patients suggest (although indirectly) the occurrence of rare mutations is not restricted to its coding regions. Finally, we demonstrate that the relative mRNA reduction directly corresponds to a protein decrease in erythroblastoid cells. Future studies will be devoted to characterizing the effect of SEC23B protein down-regulation on erythropoiesis and clarifying $S E C 23 B$ gene regulation.

\section{List of abbreviations}

bp: Base pair; COPII: Coat Protein Complex II; CDAs: Congenital

Dyserythropoietic Anemias; CDAll: Congenital Dyserythropoietic Anemia type II; ER: Endoplasmic reticulum; PCR: Polymerase Chain Reaction; qPCR:

Quantitative PCR; rH: Recombinant human; SDS-PAGE: Sodium Dodecyl

Sulphate-Polyacrylamide Gel Electrophoresis; WT: Wild-type.

\section{Acknowledgements}

The authors thank all patients and their family members for their participation in the study, and Emanuela Punzo for assistance with the figures. This work was partly supported by grants from "Progetti di Rilevante Interesse Nazionale"(PRIN), Regione Campania (L.R. 5/02, 2005), the "Francesco Fede" Department of the Second University of Naples (Grant on Normal and Pathological Hematopoiesis), and the Centre for Biomedical Genetics, the Netherlands.

\section{Author details}

'Department of Clinical Genetics, Erasmus Medical Centre, Rotterdam, the Netherlands. ${ }^{2}$ Department of Paediatrics, Second University of Naples, Naples, Italy. ${ }^{3}$ Department of Biochemistry and Biophysics, "F. Cedrangolo," Second University of Naples, Naples, Italy. ${ }^{4}$ Department of Internal Medicine, Policlinic Foundation IRCCS, Milan University, Milan, Italy. ${ }^{5}$ Centro della Microcitemia e Anemie Congenite, Galliera Hospital, Genova, Italy.

\section{Authors' contributions}

FP wrote the paper, performed the experiments, and analyzed data. AMB-A contributed to the writing of the paper and study design. SS performed experiments and analyzed data. MC contributed to patient selection and clinical characterization. LR and MDC produced erythroid precursor cell lines. GLF and Al contributed to patient selection and clinical characterization. BAO and FDR contributed to study design. SP designed the research study, selected patients, and contributed to the writing of the paper. All authors read and approved the final manuscript.

\section{Competing interests}

The authors declare that they have no competing interests

Received: 26 September 2011 Accepted: 30 December 2011

Published: 30 December 2011 
1. Marks PW, Mitus AJ: Congenital dyserythropoietic anemias. Am J Hematol 1996, 51:55-63.

2. Heimpel H, Matuschek A, Ahmed M, Bader-Meunier B, Colita A, et al: Frequency of congenital dyserythropoietic anemias in Europe. Eur J Haematol 2010, 85:20-25.

3. Crookston JH, Crookston MC, Burnie KL, Francombe WH, Dacie JV, et al: Hereditary erythroblastic multinuclearity associated with a positive acidified-serum test: a type of congenital dyserythropoietic anaemia. $\mathrm{Br} J$ Haematol 1969, 17:11-26.

4. Heimpel H, Anselstetter V, Chrobak L, Denecke J, Einsiedler B, et al: Congenital dyserythropoietic anemia type II: epidemiology, clinical appearance, and prognosis based on long-term observation. Blood 2003, 102:4576-4581.

5. Iolascon A, D'Agostaro G, Perrotta S, Izzo P, Tavano R, et al: Congenital dyserythropoietic anemia type II: molecular basis and clinical aspects. Haematologica 1996, 81:543-559.

6. Heimpel H, Kellermann K, Neuschwander N, Hogel J, Schwarz K: The morphological diagnosis of congenital dyserythropoietic anemia: results of a quantitative analysis of peripheral blood and bone marrow cells. Haematologica 2010, 95:1034-1036.

7. Renella R, Wood WG: The congenital dyserythropoietic anemias. Hematol Oncol Clin North Am 2009, 23:283-306.

8. Alloisio N, Texier P, Denoroy L, Berger C, Miraglia del Giudice E, et al: The cisternae decorating the red blood cell membrane in congenital dyserythropoietic anemia (type II) originate from the endoplasmic reticulum. Blood 1996, 87:4433-4439.

9. Anselstetter $\mathrm{V}$, Horstmann HJ, Heimpel H: Congenital dyserythropoietic anaemia, types I and I: aberrant pattern of erythrocyte membrane proteins in CDA II, as revealed by two-dimensional polyacrylamide gel electrophoresis. Br J Haematol 1977, 35:209-215.

10. Bianchi P, Fermo E, Vercellati C, Boschetti C, Barcellini W, et al: Congenital dyserythropoietic anemia type II (CDAII) is caused by mutations in the SEC23B gene. Hum Mutat 2009, 30:1292-1298.

11. Schwarz K, lolascon A, Verissimo F, Trede NS, Horsley W, et al: Mutations affecting the secretory COPII coat component SEC23B cause congenital dyserythropoietic anemia type II. Nat Genet 2009, 41:936-940.

12. Antonny B, Madden D, Hamamoto S, Orci L, Schekman R: Dynamics of the COPII coat with GTP and stable analogues. Nat Cell Biol 2001, 3:531-537.

13. Amir A, Dgany O, Krasnov T, Resnitzky P, Mor-Cohen R, et al: E109K Is a SEC23B Founder Mutation among Israeli Moroccan Jewish Patients with Congenital Dyserythropoietic Anemia Type II. Acta Haematol 2011, 125:202-207.

14. Russo R, Esposito MR, Asci R, Gambale A, Perrotta S, et al: Mutational spectrum in congenital dyserythropoietic anemia type II: identification of 19 novel variants in SEC23B gene. Am J Hematol 2010, 85:915-920.

15. Russo R, Gambale A, Esposito MR, Serra ML, Troiano A, et al: Two founder mutations in the SEC23B gene account for the relatively high frequency of CDA II in the Italian population. Am J Hematol 2011, 86:727-732.

16. Ronzoni L, Bonara P, Rusconi D, Frugoni C, Libani I, et al: Erythroid differentiation and maturation from peripheral CD34+ cells in liquid culture: cellular and molecular characterization. Blood Cells Mol Dis 2008, 40:148-155.

17. Fermo $E$, Bianchi $P$, Notarangelo LD, Binda S, Vercellati $C$, et al: CDAll presenting as hydrops foetalis: molecular characterization of two cases. Blood Cells Mol Dis 2010, 45:20-22.

18. Iolascon A, Russo R, Esposito MR, Asci R, Piscopo C, et al: Molecular analysis of 42 patients with congenital dyserythropoietic anemia type II: new mutations in the SEC23B gene and a search for a genotypephenotype relationship. Haematologica 2010, 95:708-715.

19. Fromme JC, Ravazzola M, Hamamoto S, Al-Balwi M, Eyaid W, et al: The genetic basis of a craniofacial disease provides insight into COPII coat assembly. Dev Cell 2007, 13:623-634.

20. Paccaud JP, Reith W, Carpentier JL, Ravazzola M, Amherdt M, et al: Cloning and functional characterization of mammalian homologues of the COPII component Sec23. Mol Biol Cell 1996, 7:1535-1546.

doi:10.1186/1750-1172-6-89

Cite this article as: Punzo et al: Congenital Dyserythropoietic Anemia Type II: molecular analysis and expression of the SEC23B Gene. Orphanet Journal of Rare Diseases 2011 6:89.

\section{Submit your next manuscript to BioMed Central and take full advantage of:}

- Convenient online submission

- Thorough peer review

- No space constraints or color figure charges

- Immediate publication on acceptance

- Inclusion in PubMed, CAS, Scopus and Google Scholar

- Research which is freely available for redistribution 